
\title{
R Research S Suare \\ PEX-168 Improves Insulin Resistance, Inflammatory Response and Adipokines in Simple Obese Mice and Explore the Mechanism
}

\section{Guo Zeyuan}

Yangzhou University https://orcid.org/0000-0002-2536-2062

Wu Yuting

Yangzhou University

Sun Xiaofang ( $13665278170 @ 163 . c o m$ )

Yangzhou University https://orcid.org/0000-0001-5502-0912

\section{Research}

Keywords: PEX-168, simple obesity, chemerin, omentin, Homa-IR, CRP

Posted Date: June 1st, 2021

DOI: https://doi.org/10.21203/rs.3.rs-520283/v1

License: (c) (i) This work is licensed under a Creative Commons Attribution 4.0 International License.

Read Full License 


\section{Lipids in Health and Disease}

\section{PEX-168 improves insulin resistance, inflammatory response and adipokines in simple obese mice and explore the mechanism

\author{
--Manuscript Draft--
}

\begin{tabular}{|c|c|}
\hline Manuscript Number: & LHAD-D-21-00238 \\
\hline Full Title: & $\begin{array}{l}\text { PEX-168 improves insulin resistance, inflammatory response and adipokines in simple } \\
\text { obese mice and explore the mechanism }\end{array}$ \\
\hline \multicolumn{2}{|l|}{ Funding Information: } \\
\hline Corresponding Author E-Mail: & 13665278170@163.com \\
\hline
\end{tabular}

\section{Corresponding Author Secondary}

Information:

Corresponding Author's Institution:

Northern Jiangsu People's Hospital

Corresponding Author's Secondary Institution:

First Author:

Guo Zeyuan

First Author Secondary Information:

Order of Authors:

Guo Zeyuan

Wu Yuting

Sun Xiaofang

Order of Authors Secondary Information: 


\section{Opposed Reviewers:}

Additional Information:

Question

Response

$<\mathrm{b}>$ Is this study a clinical

trial $?</ \mathrm{b}\rangle\langle\mathrm{h} r\rangle<\mathrm{i}>\mathrm{A}$ clinical trial is defined

No

by the World Health Organisation as 'any

research study that prospectively assigns

human participants or groups of humans

to one or more health-related

interventions to evaluate the effects on

health outcomes'.</i> 


\section{PEX-168 improves insulin resistance, inflammatory response and adipokines in simple obese mice and explore the mechanism} Zeyuan Guo ${ }^{1}$ Yuting $\mathrm{Wu}^{1}$ Xiaofang $\mathrm{Sun}^{2 *}$

\section{Abstract:}

Background: Polyethylene glycxol losenatide (PEX-168) is a new anti-diabetic drug and there are no reports on its weight loss effects, so we designed this trial to investigate the effect of PEX-168 on simple obese mice.

Methods: Thirty healthy C57BL/6 male mice were randomly selected and divided into a blank control group $(\mathrm{NC}, \mathrm{n}=6)$ and an obesity model group ( $\mathrm{n}=24)$, the high-fat diet-induced simple obesity mice were divided into a model control group (HF) and three different doses of PEX-168 intervention groups of low (LD), medium (MD) and high (HD) (the doses of PEX-168 were $0.03 \mathrm{mg} / \mathrm{kg}, 0.1 \mathrm{mg} / \mathrm{kg}, 0.3 \mathrm{mg} / \mathrm{kg}$ ), 6 animals in each group. The intervention groups were injected with different doses of PEX-168 intraperitoneally once a week for 12 weeks, and fasting blood glucose (FBG), body weight and food intake were measured from 1 to 12 weeks after the injection, and the activity of mice was observed, and serum insulin (INS), CRP, chemerin and omentin levels were measured after 12 weeks.

Results: Compared with the HF group, the low dose of PEX-168 could reduce the

*Correspondence: Xiaofang SUN, 13665278170@163.com

${ }^{1}$ College of Nursing, Yangzhou University, ${ }^{2}$ Department of Endocrinology, Northern Jiangsu People's

Hospital 
body weight of mice in a short period of time ( 8 weeks), and the mice in the LD and HD groups had a significant decrease in body weight $(\mathrm{P}<0.05)$; the low dose of PEX-168 could effectively improve the blood glucose and Homa-IR of mice (FBG P $<0.05$ INS, IR P $<0.001)$, but there was no statistical difference between different doses $(\mathrm{P}>0.05)$; $\mathrm{CRP}$ levels in $\mathrm{HD}$ and $\mathrm{LD}$ groups were significantly improved $(\mathrm{P}<$ $0.05)$, the levels of serum chemerin and omentin in intervention groups were significantly improved $(\mathrm{P}<0.01)$, but there was no statistical difference between the different doses $(\mathrm{P}>0.05)$.

Conclusion: Continuous 12W administration of PEX-168 significantly reduced body weight in simple obese mice, thereby improving inflammatory status, improving insulin resistance, reducing serum chemerin level and increasing serum omentin level, inhibiting the development of diabetes. PEX-168 may regulate the expression of chemerin and omentin mainly through its hypoglycemic effect.

【Key words】 PEX-168; simple obesity; chemerin; omentin; Homa-IR; CRP

\section{Introduction}

The incidence rate of obesity has doubled in the past decades, which has brought challenges to the health of the world's people $(1,2)$. Obesity not only causes other serious diseases, but also increases the financial burden of medical care(3).

Lifestyle (e.g., diet and exercise) and behavioral changes are the cornerstones of obesity management(4), but they are difficult for patient to comply and maintain, and effective non-invasive treatments will be limited(5). The risks of bariatric surgery are high and the surgery is only suitable for a small group of people(6). Considering the 
huge financial burden caused by obesity, the cost of interventions that can sustain weight loss is also critical. Therefore, new treatment options is of great significance for overweight and obese non-type 2 diabetes patients to better manage their weight, prevent or improve insulin resistance and inflammation, thereby reducing the risk of diabetes and improving the quality of life(7).

In recent years, glucagon-like peptide-1 (GLP-1) has been a hot topic of interest. GLP-1 is a peptide substance that has a series of physiological functions such as promoting insulin release, promoting the proliferation and differentiation of pancreatic $\beta$-cells, increasing satiety and reducing food intake, and has a low risk of hypoglycemia(8). Many studies have demonstrated that overweight or obese people with type 2 diabetes have a better tolerance to the GLP-1 receptor agonist liraglutide, which can reduce food intake without increasing energy consumption, so as to achieve a good weight loss goal $(9,10)$. However, due to the action of dipeptidyl peptidase IV, the half-life of GLP-1 in vivo is short, and several repeated doses are required to achieve therapeutic effects. Compared with natural GLP-1, although liraglutide is not easily and rapidly degraded by dipeptidyl peptidase IV in vivo, its half-life is also only $13 \mathrm{~h}$, and it still needs to be injected subcutaneously once a day, which makes the patient's compliance affected. PEX-168 is modified by amino acid and pegylation on the chemical structure of Exenatide, which is the first long-acting GLP-1 RA developed independently in China, and has entered the Chinese health insurance system. Its introduction for the treatment of obesity can significantly reduce medical costs. PEX-168 becomes a long-acting formulation through the modification 
of polyethylene glycol, and only needs to be administered once a week, thus increasing patient compliance.

However, research in Jessica and Tina pointed out that further research is still needed to determine the effect of GLP-1 receptor agonists on overweight or obese non-type 2 diabetic patients $(11,12)$. Studies have proven the efficacy and safety of PEX-168 in the treatment of patients with T2DM(13, 14), but the effect of PEX-168 on the simple obesity and the regulation of chemerin and omentin expression has not been reported, so we selected six indicators to evaluate the effect according to the research direction and the characteristics of PEX-168. Because obesity is a significant determinant of insulin resistance, and adipose tissue plays a key role in insulin resistance(15), and Insulin resistance is the common pathophysiological basis of obesity and type 2 diabetes(16). Diet-induced obesity is associated with chronic low-grade inflammation of the hypothalamus. Metabolic inflammation is a significant feature of obesity. Obesity and type 2 diabetes are both associated with the increased risk of cardiovascular disease (CVD), and are now considered to have inflammatory components(17). CRP is now one of the most powerful predictors of inflammatory and lipid markers of cardiovascular events(18). Obesity, inflammation and insulin resistance are closely related, obese patients without dyslipidemia, IR, inflammatory state, and impaired fasting blood sugar have a very low risk of developing diabetes(19). Serum omentin and chemerin are newly discovered novel adipokines. As an inflammatory chemokine and adipokine, Chemerin is considered to be an intermediate factor between obesity and T2DM(20). Recent studies have shown that 
plasma levels and gene expression of omentin-1 are negatively associated with obesity and insulin resistance(21). Both are closely related to obesity and disorders of glucolipid metabolism, and can reflect the hyperlipidemia and inflammatory state of patients.

Therefore, the aim of this study was to observe the effects of different doses of PEX-168 on body weight, intake, Homa-IR, CRP and adipokines chemerin and omentin in simple obese mice induced by high-fat diet, to observe whether there was variability between different doses, and to provide a basis for subsequent clinical studies.

\section{Materials and methods}

\subsection{Reagents and materials}

Long-acting glucagon-like peptide-1 analogue polyethylene glycol losenatide (PEX-168), (test article) was provided by Jiangsu Haosen Pharmaceutical Co., Ltd, lot number:H20190024, specification:0.5ML $(0.1 \mathrm{mg})$ per bottle, stored at $4 \sim 8^{\circ} \mathrm{C}$, elisa kit was purchased from Nanjing Liko Biotechnology Co., Ltd. The basic feed and high-fat feed were purchased from Yangzhou University College of Veterinary Medicine and Jiangsu Medison Biomedical Co., Ltd. respectively. This experiment was approved by the Animal Ethics Committee of YZU University.

\subsection{Animals}

\subsubsection{Animal model and test methods}

Thirty six-week-old SPF-grade male C57BL/6 mice were purchased from the College of Agriculture, Yangzhou University, and housed in cages at room 
111

112

temperature of $18-24^{\circ} \mathrm{C}$. They were first fed with normal chow for one week for adaptation, and exposed to light for $12 \mathrm{H}$ daily, with unlimited access to chow and water. This experiment was approved by the Animal Ethics Committee of Yangzhou University. Starting from the age of seven weeks, they were randomly divided into five groups, and one group (ND group, $\mathrm{n}=6$ ) was randomly selected from the five groups as a blank control group and continued to be fed with ordinary feed, and the rest of the groups were fed high-fat feed to establish an obesity model until the weight of the obesity model group exceeded $20 \%$ of the control group, and there was no difference in body weight between the groups, which means that the model is successful.

After successful modeling, the four obesity model groups were randomly divided into three intervention groups: low dose $(0.03 \mathrm{mg} / \mathrm{kg}$ ) group (LD group, $\mathrm{n}=6)$, medium dose $(0.1 \mathrm{mg} / \mathrm{kg})$ group (MD group, $\mathrm{n}=6)$, high dose $(0.33 \mathrm{mg} / \mathrm{kg})$ group (HD group, $n=6$ ) and a control group (HF group, $n=6$ ).

After grouping, the three intervention groups and the control group transitioned from a high-fat diet to a normal diet in one week, the intervention groups were intraperitoneally administered different doses of PEX-168 once a week according to the grouping for 12 weeks. The body weight and food intake of the mice were measured regularly every day. At the end of the animal experiment, all mice were fasted overnight for $12 \mathrm{~h}$, blood was collected from the eyeballs, and the supernatant was collected after centrifugation at $5000 \mathrm{r} / \mathrm{min}$ for $15 \mathrm{~min}$.

\subsubsection{Indicators and measurement}


(1) General condition: daily observation of the mice's activities, including observation of their appearance, urine, stool, activity, gait, spirit, appetite, and any abnormal conditions.

(2) Determination of body weight, food intake and blood glucose: The body weight of mice was measured regularly every day, the appropriate amount of food was put in each time, the feed was weighed before putting in, and the weight of the remaining feed was weighed the next day (the large pieces of residue in the cage box of each group were weighed and recorded, and the residue crumbs were ignored), and the daily food intake was calculated. Mice were fasted for $12 \mathrm{H}$ each week without restriction of water intake, and their fasting blood glucose was measured regularly by tail-tip cutting the next morning for 12 weeks.

(3) Serum biochemical analysis: At the end of 12 weeks intervention, all mice were fasted overnight for $12 \mathrm{H}$, and they were executed by cervical dislocation after eye blood collection, and the supernatant was preserved after centrifugation at 5000r/min for 15min, and the levels of FBG, INS and CRP were detected, and the insulin resistance index (Homa-IR) was calculated according to the steady-state model method formula: Homa-IR index = FBG $(\mathrm{mmol} / \mathrm{L}) \mathrm{x}$ INS $(\mathrm{mIU} / \mathrm{L}) / 22.5$, and determine the serum chemerin and omentin levels in mice according to the kit instructions.

\subsection{Statistical analysis}

Analysis was performed using SPSS 22.0. The measurement data were expressed as mean \pm standard deviation $(\mathrm{x} \pm \mathrm{s})$ and t-test was used; one-way ANOVA was used 
155

156

157

158

159

160

161

162

163

164

165

for comparison between multiple groups; Pearson correlation analysis was used for correlation; $\mathrm{P}<0.05$ was considered to be statistically significant.

\section{Results}

\subsection{General conditions}

During the experiment, all three groups of mice in the intervention group had a decrease in activity and water intake two to three days after being injected with PEX-168 in the first two weeks, the inhibitory effect gradually improved with the extension of the intervention time, and the LD group recovered the fastest, During the intervention period, all mice had dark and shiny coats.

\subsection{Effect on the intake of mice}

Food intake in the three intervention groups dropped sharply on the first day of the intervention in the first three weeks and gradually increased in the second six days., and the food intake suppression effect gradually weakened with the duration of the intervention (Figure 1). Compared with the HF group, the food intake of the three intervention groups was significantly reduced in the pre-intervention period, and the difference was statistically significant $(\mathrm{LD} P<0.05$, MD $\mathrm{P}=0.004<0.01$, $\mathrm{HD} \mathrm{P}=0.002$ $<0.01)$. In the late intervention period, the difference in food intake between the HF and LD groups was not statistically significant $(\mathrm{P}>0.05)$.

Figure 1 The food intake of each group was compared for 12 weeks $(\bar{x} \pm s, g)$

\subsection{Effects on body weight, blood glucose and insulin in mice}

The mean weight of the mice in the blank control group before the start of the experiment was $21.89 \mathrm{~g}$. There was no statistical difference in weight between all the 
177 obese mice groups $(\mathrm{P}>0.05)$. During the intervention period, the body weight of mice

178 in the HF group was relatively stable. After intervention, the body weight of the mice

179 in the three groups was still higher than that in the ND group, and the difference was

180 statistically significant $(\mathrm{P}<0.001)$. Compared with the HF group, the weight of the

181 mice in the three groups had a downward trend, among which the body weight of

182 mice in MD and HD groups decreased significantly and the difference was

183 statistically significant $(\mathrm{MD} \mathrm{P}=0.009<0.01$, HD $\mathrm{P}=0.025<0.05)$. The weight loss of

184 mice in LD group was statistically significant in the first eight weeks $(\mathrm{P}<0.05)($ Table

$1852)$.

186 Before the intervention, the mean FBG of mice in the ND group was 7.08

$187 \mathrm{mmol} / \mathrm{L}$ and that of obese mice in the four groups was $7.89 \mathrm{mmol} / \mathrm{L}$. The FBG was

188 within the normal range, indicating that the mice were all non-diabetic simple obese

189 mice. After intervention, the levels of FBG, INS and Homa-IR of mice in all four

190 groups were significantly higher than those in the ND group, with statistically

191 significant differences $(\mathrm{P}<0.001)$, while compared with the HF group, the levels of

192 FBG, INS and Homa-IR of obese mice in the three intervention groups were

193 significantly lower, with statistically significant differences (FBG $\mathrm{P}<0.05$, INS

194 Homa-IR $\mathrm{P}<0.001)$; while there were no significant differences in the improvement

195 of FBG, INS and Homa-IR in mice between the three intervention groups. In the 10th

196 week of the intervention, a transient hypoglycaemic event occurred in the MD and

197 HD groups, with four and three mice having FBG below $5 \mathrm{mmol} / \mathrm{L}$, with the

198 incidence of $67 \%$ and $50 \%$, respectively, followed by a return to normal levels. 
Figure 2 Changes in weight after 12 weeks treatment, relative to baseline

Table 1 Comparison of weight、FBG、FINS、Homa-IR in each group (`x $\pm s$ )

\begin{tabular}{cccccc}
\hline Groups & Quantity & weight $(\mathrm{g})$ & FBG $(\mathrm{mmol} / \mathrm{L})$ & FINS $(\mathrm{mIU} / \mathrm{L})$ & Homa-IR \\
\hline NC & $\mathrm{n}=5$ & $23.52 \pm 0.90^{\mathrm{a}}$ & $7.40 \pm 0.12^{\mathrm{a}}$ & $7.70 \pm 0.17^{\mathrm{a}}$ & $2.59 \pm 0.05^{\mathrm{a}}$ \\
HF & $\mathrm{n}=6$ & $31.57 \pm 2.28$ & $8.33 \pm 0.15$ & $10.01 \pm 0.10$ & $3.79 \pm 0.08$ \\
LD & $\mathrm{n}=5$ & $31.95 \pm 2.20^{\mathrm{b}}$ & $8.02 \pm 0.15^{\mathrm{ab}}$ & $8.50 \pm 0.28^{\mathrm{ab}}$ & $3.1 \pm 0.14^{\mathrm{ab}}$ \\
MD & $\mathrm{n}=6$ & $28.67 \pm 0.91^{\mathrm{ab}}$ & $8.08 \pm 0.17^{\mathrm{ab}}$ & $8.62 \pm 0.24^{\mathrm{ab}}$ & $3.17 \pm 0.13^{\mathrm{ab}}$ \\
HD & $\mathrm{n}=5$ & $29.04 \pm 1.87^{\mathrm{ab}}$ & $7.94 \pm 0.21^{\mathrm{ab}}$ & $8.65 \pm 0.25^{\mathrm{ab}}$ & $3.12 \pm 0.07^{\mathrm{ab}}$ \\
\hline
\end{tabular}

$201{ }^{a} \mathrm{P}<0.05$ vs the HF group; ${ }^{\mathrm{b}} \mathrm{P}<0.05$ vs the ND group

202 3.4 Effects on CRP, adipokines chemerin and omentin in mice

203 As shown in Table 3, compared with the ND group, there were statistical

204 differences in the levels of CRP, chemerin and omentin in the four groups (chemerin

205 omentin $\mathrm{P}<0.001$, CRP P $<0.05)$. CRP was significantly lower in the MD and HD

206 groups than that in the HF group, and the differences were statistically significant $(\mathrm{P}<$

207 0.05); There was no difference in the improvement between the MD and HD groups

208 ( $P>0.05)$; the serum chemerin levels of mice in all three intervention groups were

209 lower than those in the HF group, and the difference was statistically significant $(\mathrm{P}<$

$2100.01)$; the serum omentin levels of mice in all three intervention groups were higher

211 than those in the HF group, and the difference was statistically significant $(\mathrm{P}<0.001)$;

212 There was no statistical difference in the improvement of serum chemerin and

213 omentin between the 3 different doses of PEX-168 groups in mice $(\mathrm{P}>0.05)$.

214 Insulin resistance in mice was negatively correlated with serum omentin levels

$215(\mathrm{r}=-0.836, \mathrm{P}<0.001)$ and positively correlated with serum chemerin levels $(\mathrm{r}=0.828$, 
$\mathrm{P}<0.001)$

Table 2 Comparison of CRP、Chemerin and Omentin in each group (` $\mathrm{x} \pm \mathrm{s})$

\begin{tabular}{cccc}
\hline Groups & CRP $(\mathrm{ug} / \mathrm{L})$ & Chemerin $(\mathrm{ng} / \mathrm{L})$ & Omentin $(\mathrm{ng} / \mathrm{L})$ \\
\hline NC & $1327.39 \pm 27.05^{\mathrm{a}}$ & $50.85 \pm 1.19^{\mathrm{a}}$ & $147.76 \pm 1.62^{\mathrm{a}}$ \\
$\mathrm{HF}$ & $1410.48 \pm 25.45$ & $56.79 \pm 0.85$ & $131.14 \pm 3.14$ \\
LD & $1403.08 \pm 35.26$ & $54.65 \pm 1.47^{\mathrm{a}}(\mathrm{p}=0.007)$ & $139.67 \pm 3.88^{\mathrm{a}}(\mathrm{p}=0.000)$ \\
MD & $1370.17 \pm 31.32^{\mathrm{a}}(\mathrm{p}=0.033)$ & $54.30 \pm 1.33^{\mathrm{a}}(\mathrm{p}=0.001)$ & $139.10 \pm 3.22^{\mathrm{a}}(\mathrm{p}=0.000)$ \\
HD & $1370.44 \pm 33.90^{\mathrm{a}}(\mathrm{p}=0.042)$ & $54.66 \pm 1.02^{\mathrm{a}}(\mathrm{p}=0.007)$ & $137.58 \pm 2.83^{\mathrm{a}}(\mathrm{p}=0.000)$ \\
\hline
\end{tabular}
intake was unstable during the intervention and was gradually tolerated by the mice as the intervention progressed and the inhibition of food intake diminished. This may be

${ }^{a} \mathrm{P}<0.05$ vs the HF group; ${ }^{\mathrm{b}} \mathrm{P}<0.05$ vs the ND group

Figure 3 Change in the level of Homa-IR in each group (` $x \pm s, u g / L)$

Figure 4 Change in the level of CRP in each group (`x $\pm s, u g / L)$

Figure5 Change in the level of chemerin in each group (` $\mathrm{x} \pm \mathrm{s}, \mathrm{ng} / \mathrm{L})$

Figure 6 Change in the level of omentin in each group $(` x \pm s, n g / L)$

\section{Discussion}

\section{Body weight and food intake}

In the present study, low doses of PEX-168 inhibited the progression of obesity

in the short term, and medium to high concentrations of PEX-168 inhibited the

development of obesity in the long term. The corresponding changes in food intake and body weight also demonstrated that the weight-reducing effect of PEX-168, like other GLP-1 analogues, was mainly through inhibition of intake, which is also consistent with animal experiments with liraglutide. However, the decrease in food 
such as gastrointestinal discomfort. The most common adverse reaction of GLP-1 RA is gastrointestinal reactions, which gradually decreased with longer dosing time and was significantly dose-dependent(22). GLP-1 also has a profound inhibitory effect on gastric emptying. The delayed gastric emptying induced by GLP-1 is influenced by a rapid response at the level of vagal activation, and the delay in gastric emptying by GLP-1 is significantly attenuated after long-term administration of GLP-1 analogues(23), which was also consistent with the changes in intake of the intervention groups in this experiment. In addition, PEX-168 is a long-acting preparation with a more sustained hypoglycaemic effect and less effect on gastric emptying, leading to a gradual weakening of the inhibitory effect on food intake.

\section{Insulin resistance}

In this study, the hypoglycemic effect of PEX-168 on simple obese mice can be manifested at low doses, and all three doses of PEX-168 inhibited the development of prediabetes and improved insulin resistance in non-diabetic simple obese mice. In Khound's animal experiment(24), it was shown that elevated GLP-1 prevented the overproduction of VLDL and improved insulin resistance induced by a high-fat diet in mice, which is consistent with the results of the present study.

However, clinical trials have confirmed the safety of PEX-168 in regulating blood glucose in T2DM patients, and the risk of hypoglycaemia is very low with monotherapy. In this study, PEX-168 was used in non-diabetic simple obese mice, and hypoglycaemic events occurred in the middle and high dose groups, indicating that there is a certain risk of hypoglycaemia when PEX-168 intervenes in simple obese 
mice with normal blood glucose, and the low dose should be considered as the starting dose.

\section{Inflammatory reaction}

C-reactive protein is a sensitive marker of systemic inflammation synthesised by the liver. It is a non-specific acute phase reactant that has traditionally been used to detect acute injury, infection and inflammation(25). Recent studies have shown that diabetes, obesity and elevated levels of CRP, TNF-alpha and leptin are closely $\operatorname{associated}(26)$.

In the present study, the level of CRP was significantly elevated in obese mice compared to ND, which is consistent with previous reports. The association between obesity and elevated serum CRP levels has been well explained by pathophysiological mechanisms. In our experiments, only the MD and HD groups showed significant improvement in inflammation, and both body weight and the level of CRP in the LD group were not statistically different from the HF group, indicating that PEX-168 at medium doses and above significantly reduces body weight in simple obese mice, thereby improving the inflammatory reaction and reducing cardiovascular risk.

\section{Adipose factor}

In our study, the level of serum chemerin was significantly higher and the level of serum omentin was significantly lower in obese mice compared to the ND group. The concentration of chemerin was associated with BMI, adipocyte volume and number, and in adult obese patients, body weight was significantly and positively correlated with circulating chemerin levels(27). Batista assessed the concentration of 
omentin in obese patients(28), normal weight subjects showed higher levels of omentin than overweight and obese patients, which is also consistent with our findings.

Interestingly, although the LD group did not lose weight at the end of intervention, the levels of FBG, INS, Homa-IR, chemerin and omentin were improved, and the improvements were equal across doses. In Yang's experiment(29), it was suggested that the GLP-1 analogue liraglutide could improve insulin resistance in high-fat diet-induced obese mice by improving endoplasmic reticulum stress, thereby reducing the chemerin level. (29). $\mathrm{K}$. Tan and Yan pointed out that (21, 30)insulin and glucose could significantly and dose-dependently reduced omentin-1 mRNA and protein levels, and plasma level of omentin-1 was independently and negatively correlated with fasting insulin and HOMA-IR. K. Tan also pointed out that BMI or WHR is unlikely to be responsible for the decrease in omentin-1 mRNA expression and protein levels in female PCOS patients. In our study, IR was highly and significantly correlated with both chemerin and omentin, so we speculate that the regulation of chemerin and omentin expression by PEX-168 may be mainly related to the hypoglycaemic effect of PEX-168, and the weight-reducing effect of PEX-168 is unlikely to be the reason for the changes in both, which needs to be demonstrated by further experimental studies.

\section{Limitation}

It has been suggested that(11)non-type 2 diabetic patients lose more weight than type 2 diabetic patients when treated with GLP-1 agonists for weight loss, and this 
300

301

302

303

304

305

306

307

308

309

310

311

312

could not be confirmed in our experimental design without the inclusion of a diabetic obesity model group; the intervention period was not long enough, in clinical trials it was noted that PEX-168 blood levels reached stability after four weeks of intervention, but in our study the measurements of the mice only started to stabilize at a later stage, so our intervention period should be extended.

\section{Conclusion}

In summary, our data suggest that in non-diabetic simple obese mice, the anti-diabetic drug PEX-168 can well reduce body weight, improve insulin resistance, reduce the inflammatory reaction, reduce chemerin and increase omentin levels, and prevent the development of prediabetes. PEX-168 regulates the expression of chemerin and omentin probably mainly through its hypoglycaemic effects, and the weight-reducing effect of PEX-168 is unlikely to be the reason for the changes in both.

We will improve the experimental design and conduct further prospective clinical studies in the future.

\section{Abbreviations}

PEX-168: Polyethylene glycxol losenatide; WHR: Waist-to-hip ratio; Homa-IR: Insulin resistance index; FBG: Fasting blood glucose INS: Insulin; CRP: C-reactive protein; BMI: Body mass index; PCOS: Polycystic ovarian syndrome

\section{Ethics approval and consent to participate}

Not applicable

\section{Consent for publication}

All authors have seen the manuscript and approved to submit to your journal. 


\section{Availability of data and materials}

Data and material would be supplied based on reasonable request.

\section{Funding}

Not applicable

\section{Acknowledgements}

The authors thank Yangzhou University and Northern Jiangsu People's Hospital

for their support of this study.

\section{Authors' contributions}

Sun has made substantial contributions to conception and design. Guo and $\mathrm{Wu}$

have carried out all trials and conducted statistical analysis. Guo has drafted the

manuscript and sun has helped with the drafting. All authors read and approved the

final manuscript.

\section{Competing interests}

The authors declare that they have no competing interests.

\section{Reference}

1. Andolfi C, Fisichella PM. Epidemiology of Obesity and Associated Comorbidities. Journal of laparoendoscopic \& advanced surgical techniques Part A. 2018;28(8):919-24.

2. Williams R, Alexander G, Armstrong I, Baker A, Bhala N, Camps-Walsh G, et al. Disease burden and costs from excess alcohol consumption, obesity, and viral hepatitis: fourth report of the Lancet Standing Commission on Liver Disease in the UK. Lancet (London, England). 2018;391(10125):1097-107.

3. Liang Y, Qi Y. Developmental trajectories of adolescent overweight/obesity in China: socio-economic status correlates and health consequences. Public health. 2020;185:246-53.

4. Rock CL, Flatt SW, Pakiz B, Quintana EL, Heath DD, Rana BK, et al. Effects of diet composition on weight loss, metabolic factors and biomarkers in a 1-year weight loss intervention in obese women examined by baseline insulin resistance status. Metabolism: clinical and experimental. 2016;65(11):1605-13.

5. Kim DD, Basu A. Estimating the Medical Care Costs of Obesity in the United States: Systematic Review, Meta-Analysis, and Empirical Analysis. Value in health : the journal of the International Society for Pharmacoeconomics and Outcomes Research. 2016;19(5):602-13. 
352

353

354

355

356

357

358

359

360

361

362

363

364

365

366

367

368

369

370

371

372

373

374

375

376

377

378

379

380

381

382

383

384

385

386

387

388

389

390

391

392

393

394

395

6. Tewksbury C, Crowley N, Parrott JM, Andromalos L, Isom KA, Smith E, et al. Weight Loss Prior to Bariatric Surgery and 30-Day Mortality, Readmission, Reoperation, and Intervention: an MBSAQIP Analysis of 349,016 Cases. Obesity surgery. 2019;29(11):3622-8.

7. Neeland IJ, Turer AT, Ayers CR, Powell-Wiley TM, Vega GL, Farzaneh-Far R, et al. Dysfunctional adiposity and the risk of prediabetes and type 2 diabetes in obese adults. Jama. 2012;308(11):1150-9.

8. Klinger S, Poussin C, Debril MB, Dolci W, Halban PA, Thorens B. Increasing GLP-1-induced beta-cell proliferation by silencing the negative regulators of signaling CAMP response element modulator-alpha and DUSP14. Diabetes. 2008;57(3):584-93.

9. van Can J, Sloth B, Jensen CB, Flint A, Blaak EE, Saris WH. Effects of the once-daily GLP-1 analog liraglutide on gastric emptying, glycemic parameters, appetite and energy metabolism in obese, non-diabetic adults. International journal of obesity (2005). 2014;38(6):784-93.

10. Tronieri JS, Wadden TA, Walsh OA, Berkowitz RI, Alamuddin N, Gruber K, et al. Effects of liraglutide plus phentermine in adults with obesity following 1 year of treatment by liraglutide alone: $A$ randomized placebo-controlled pilot trial. Metabolism: clinical and experimental. 2019;96:83-91.

11. Vilsbøll T, Christensen M, Junker AE, Knop FK, Gluud LL. Effects of glucagon-like peptide-1 receptor agonists on weight loss: systematic review and meta-analyses of randomised controlled trials. BMJ (Clinical research ed). 2012;344:d7771.

12. Potts JE, Gray LJ, Brady EM, Khunti K, Davies MJ, Bodicoat DH. The Effect of Glucagon-Like Peptide 1 Receptor Agonists on Weight Loss in Type 2 Diabetes: A Systematic Review and Mixed Treatment Comparison Meta-Analysis. PloS one. 2015;10(6):e0126769.

13. Shuai Y, Yang G, Zhang Q, Li W, Luo Y, Ma J, et al. Efficacy and safety of polyethylene glycol loxenatide monotherapy in type 2 diabetes patients: A multicentre, randomized, double-blind, placebo-controlled phase 3a clinical trial. Diabetes, obesity \& metabolism. 2021;23(1):116-24.

14. Gao F, Lv X, Mo Z, Ma J, Zhang Q, Yang G, et al. Efficacy and safety of polyethylene glycol loxenatide as add-on to metformin in patients with type 2 diabetes: A multicentre, randomized, double-blind, placebo-controlled, phase $3 \mathrm{~b}$ trial. Diabetes, obesity \& metabolism. 2020;22(12):2375-83.

15. Miao Z, Alvarez M, Ko A, Bhagat $Y$, Rahmani E, Jew B, et al. The causal effect of obesity on prediabetes and insulin resistance reveals the important role of adipose tissue in insulin resistance. PLoS genetics. 2020;16(9):e1009018.

16. Bondue B, Wittamer V, Parmentier M. Chemerin and its receptors in leukocyte trafficking, inflammation and metabolism. Cytokine \& growth factor reviews. 2011;22(5-6):331-8.

17. Masters SL, Latz E, O'Neill LA. The inflammasome in atherosclerosis and type 2 diabetes. Science translational medicine. 2011;3(81):81ps17.

18. Szmitko PE, Verma S. C-reactive protein and the metabolic syndrome: useful addition to the cardiovascular risk profile? Journal of the cardiometabolic syndrome. 2006;1(1):66-9; quiz 70-1.

19. Sung KC, Lee MY, Kim YH, Huh JH, Kim JY, Wild SH, et al. Obesity and incidence of diabetes: Effect of absence of metabolic syndrome, insulin resistance, inflammation and fatty liver. Atherosclerosis. 2018;275:50-7.

20. Ernst MC, Sinal CJ. Chemerin: at the crossroads of inflammation and obesity. Trends in endocrinology and metabolism: TEM. 2010;21(11):660-7.

21. Yan P, Li L, Yang M, Liu D, Liu H, Boden G, et al. Effects of the long-acting human glucagon-like peptide-1 analog liraglutide on plasma omentin-1 levels in patients with type 2 diabetes mellitus. Diabetes research and clinical practice. 2011;92(3):368-74. 
396 22. Brown E, Cuthbertson DJ, Wilding JP. Newer GLP-1 receptor agonists and obesity-diabetes. 397 Peptides. 2018;100:61-7.

398 23. Nauck MA, Kemmeries G, Holst JJ, Meier JJ. Rapid tachyphylaxis of the glucagon-like peptide 399 1-induced deceleration of gastric emptying in humans. Diabetes. 2011;60(5):1561-5.

400 24. Khound R, Taher J, Baker C, Adeli K, Su Q. GLP-1 Elicits an Intrinsic Gut-Liver Metabolic Signal to 401 Ameliorate Diet-Induced VLDL Overproduction and Insulin Resistance. Arteriosclerosis, thrombosis, 402 and vascular biology. 2017;37(12):2252-9.

403 25. Backes JM, Howard PA, Moriarty PM. Role of C-reactive protein in cardiovascular disease. The 404 Annals of pharmacotherapy. 2004;38(1):110-8.

405 26. Mirza S, Hossain M, Mathews C, Martinez P, Pino P, Gay JL, et al. Type 2-diabetes is associated 406 with elevated levels of TNF-alpha, IL-6 and adiponectin and low levels of leptin in a population of 407 Mexican Americans: a cross-sectional study. Cytokine. 2012;57(1):136-42.

408 27. Rowicka G, Dyląg H, Chełchowska M, Weker H, Ambroszkiewicz J. Serum Calprotectin and 409 Chemerin Concentrations as Markers of Low-Grade Inflammation in Prepubertal Children with Obesity. 410 International journal of environmental research and public health. 2020;17(20).

411 28. de Souza Batista CM, Yang RZ, Lee MJ, Glynn NM, Yu DZ, Pray J, et al. Omentin plasma levels and 412 gene expression are decreased in obesity. Diabetes. 2007;56(6):1655-61.

413 29. Yang J, Ao N, Du J, Wang X, He Y. Protective effect of liraglutide against ER stress in the liver of 414 high-fat diet-induced insulin-resistant rats. Endocrine. 2015;49(1):106-18.

415 30. Tan BK, Adya R, Farhatullah S, Lewandowski KC, O'Hare P, Lehnert H, et al. Omentin-1, a novel 416 adipokine, is decreased in overweight insulin-resistant women with polycystic ovary syndrome: ex vivo 417 and in vivo regulation of omentin-1 by insulin and glucose. Diabetes. 2008;57(4):801-8. 


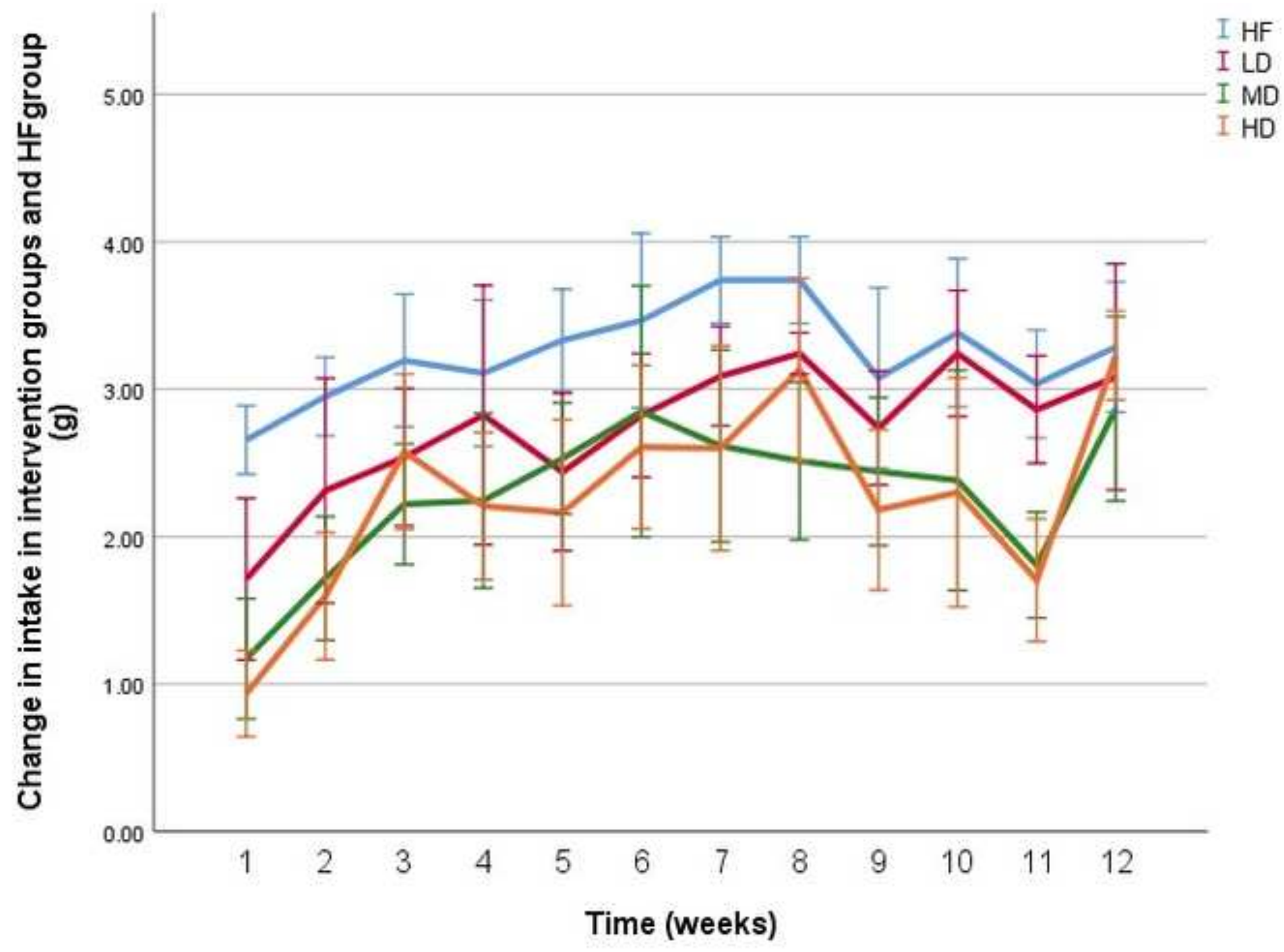




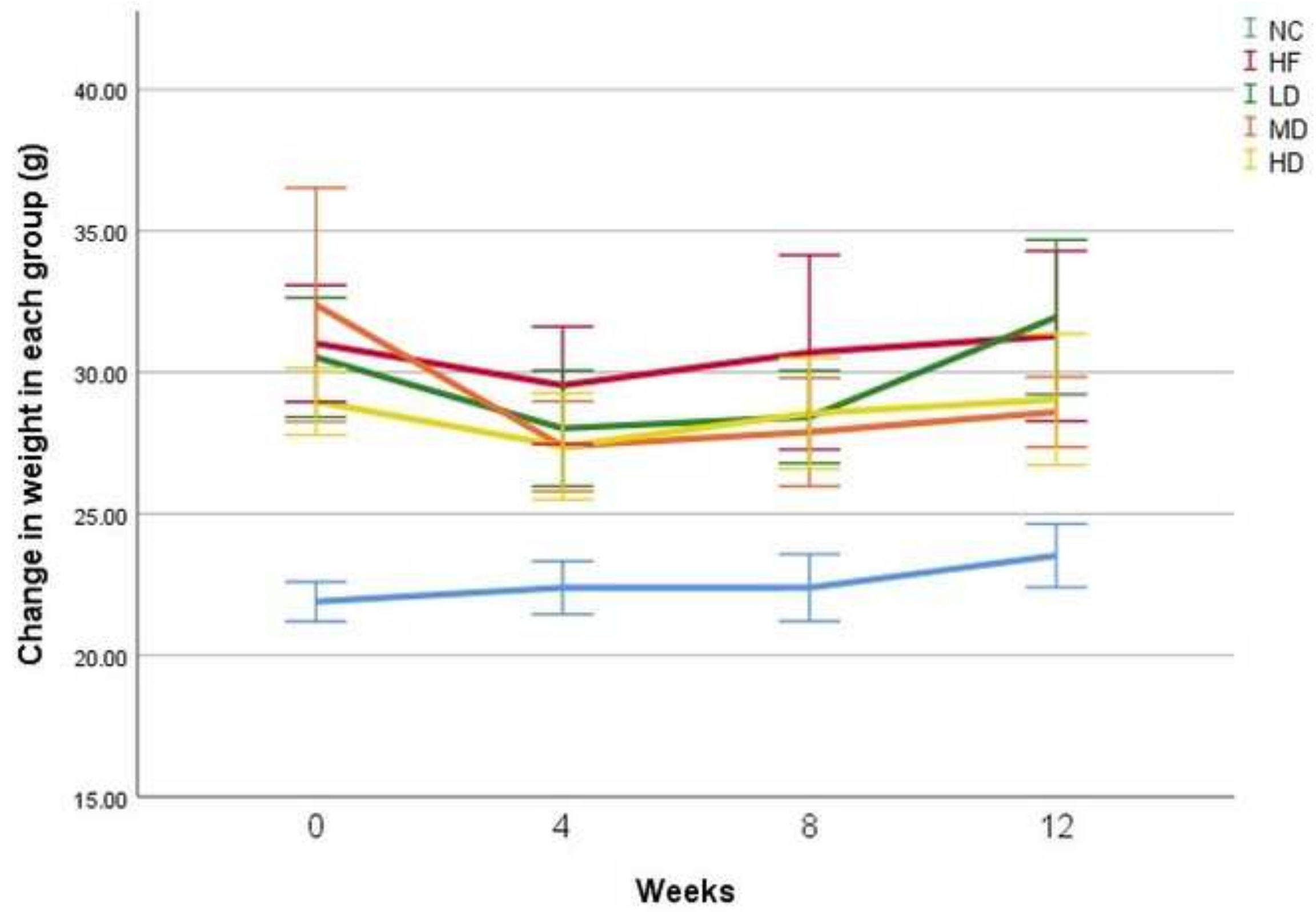




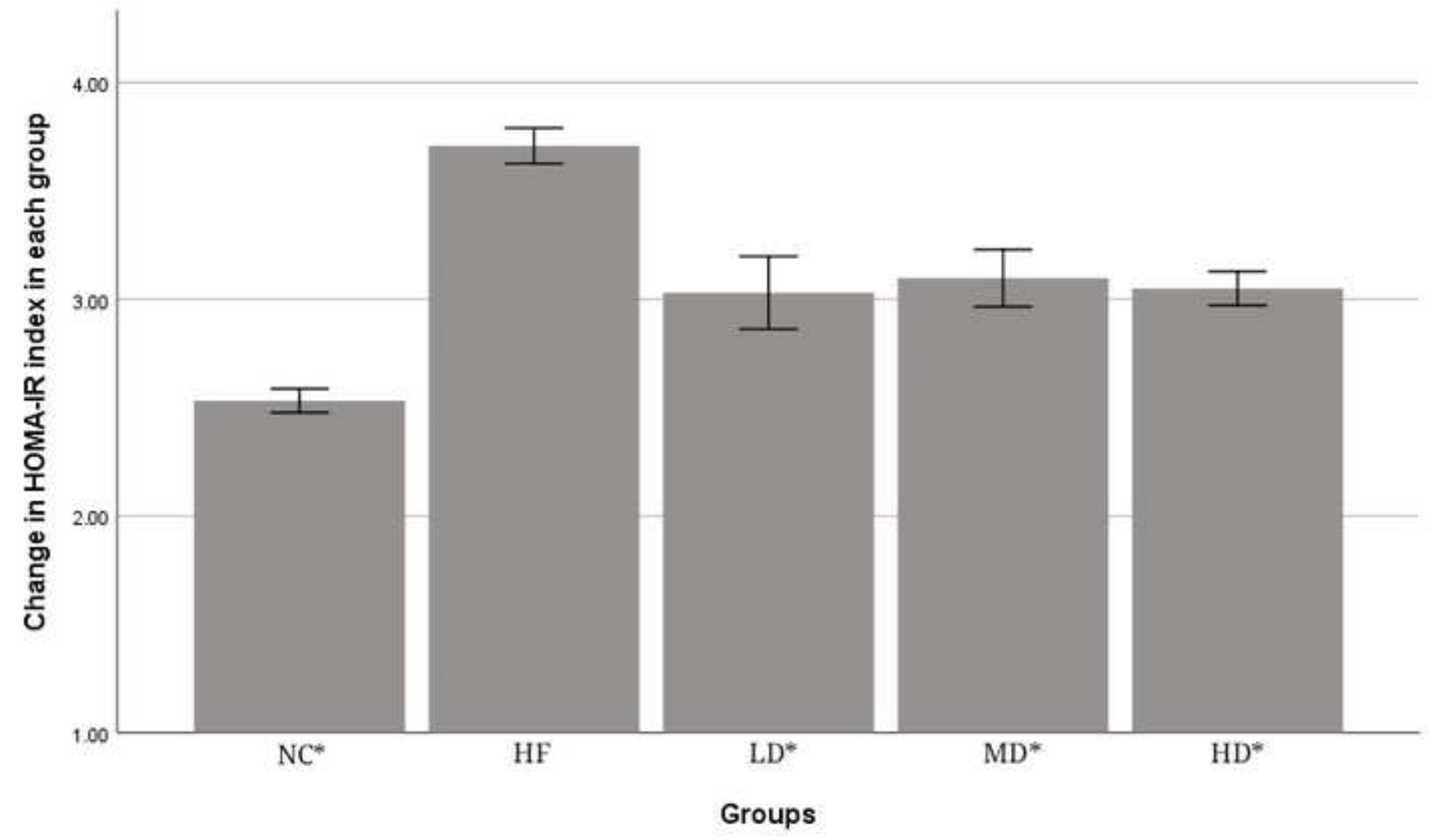




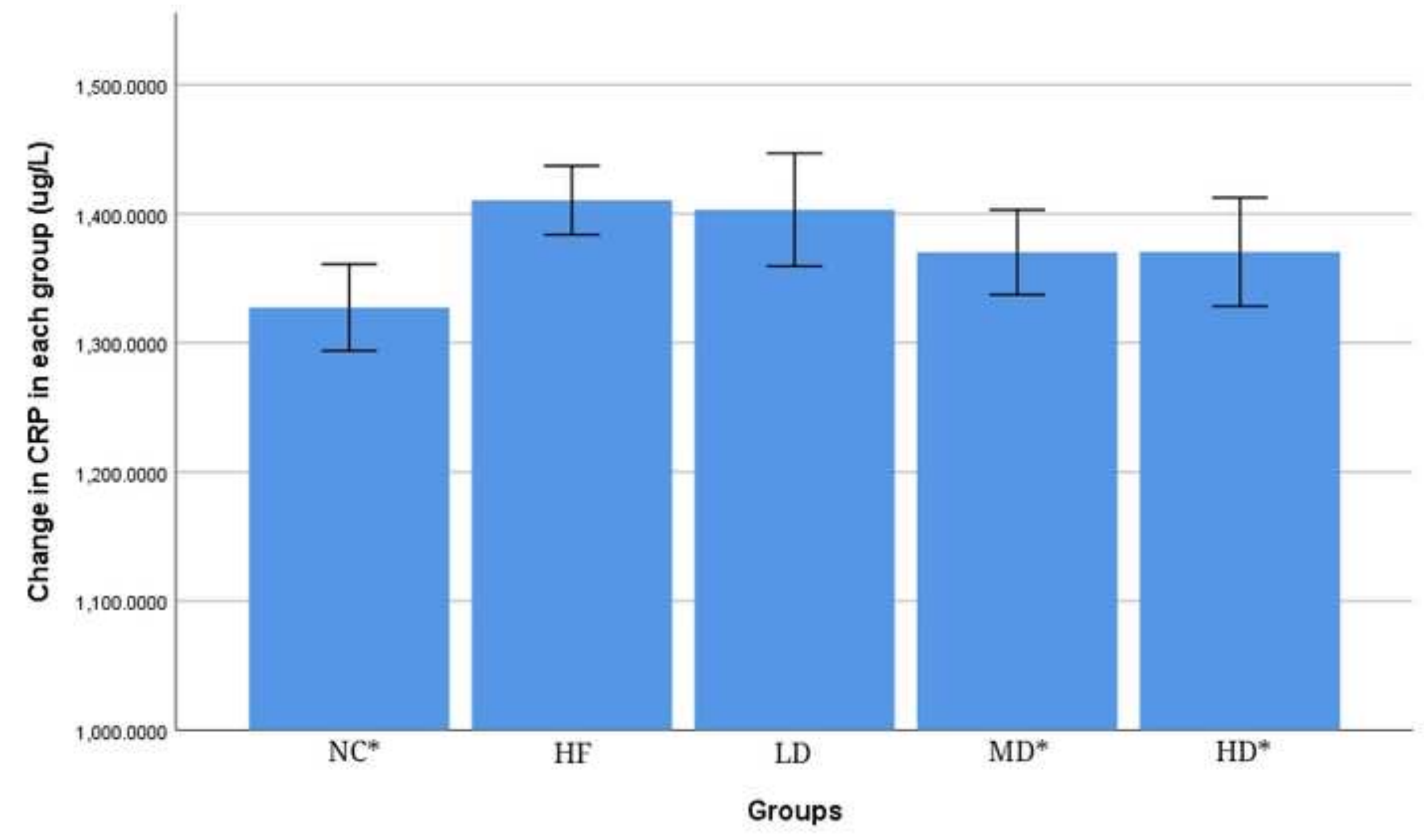




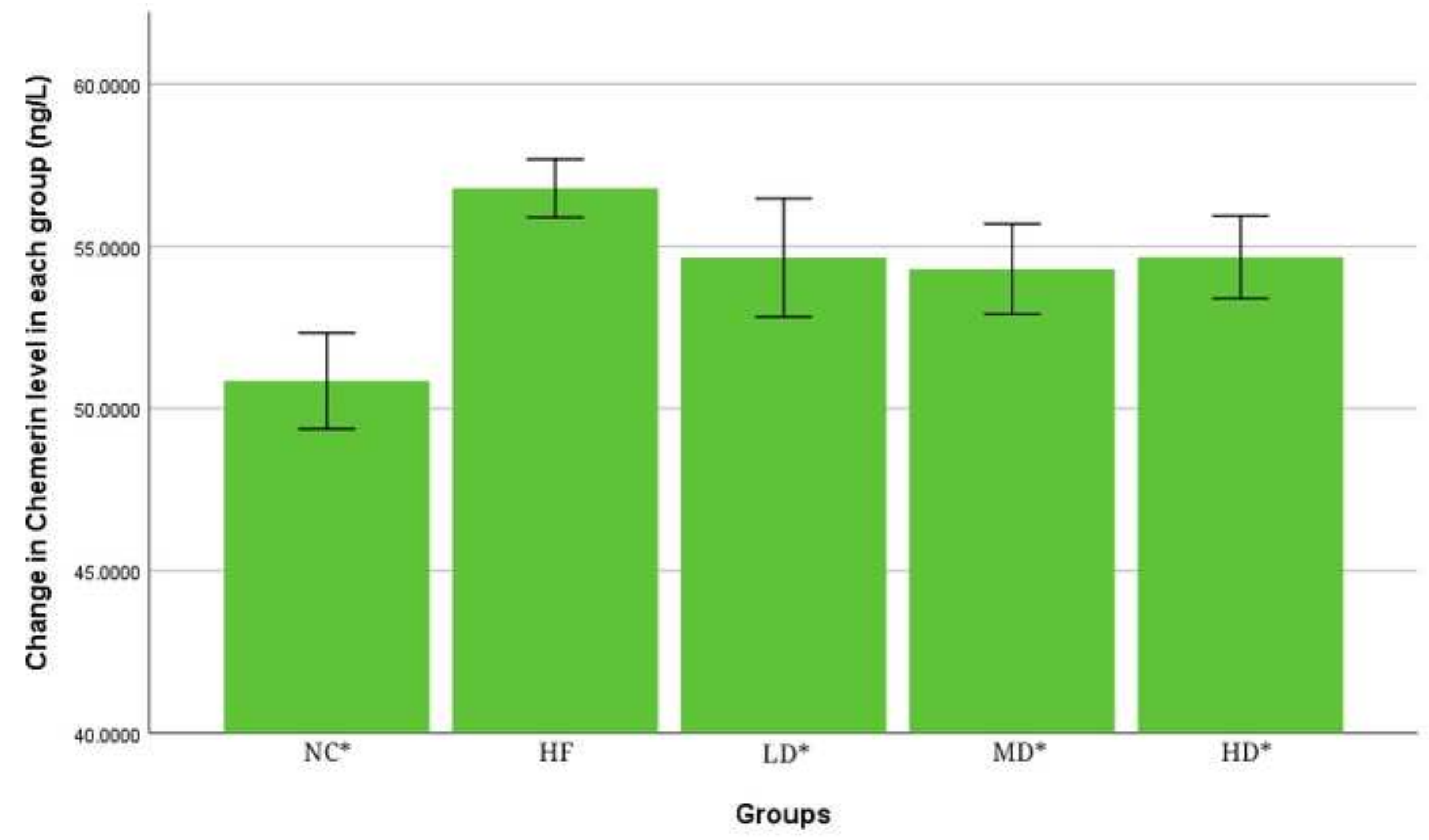




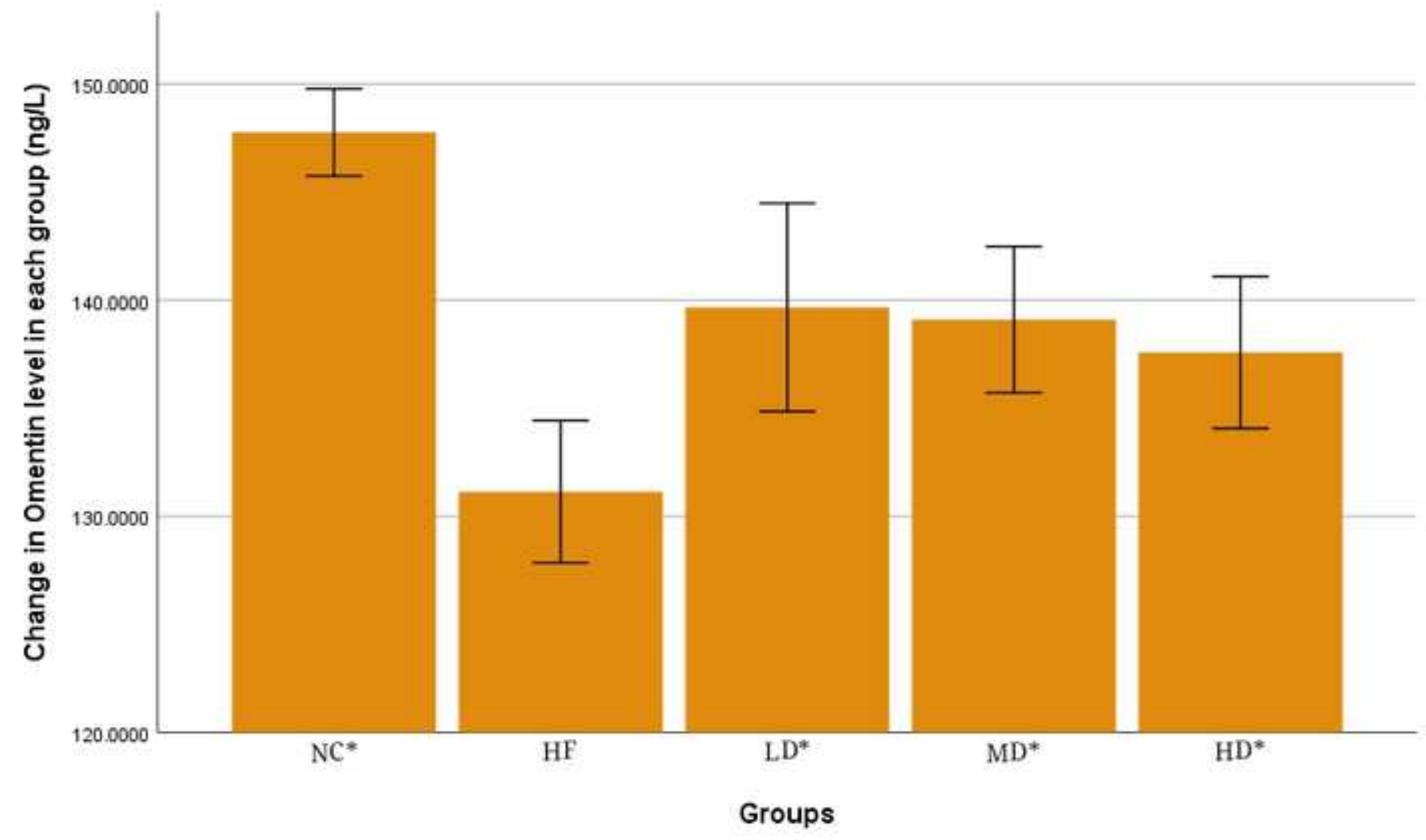


Figures

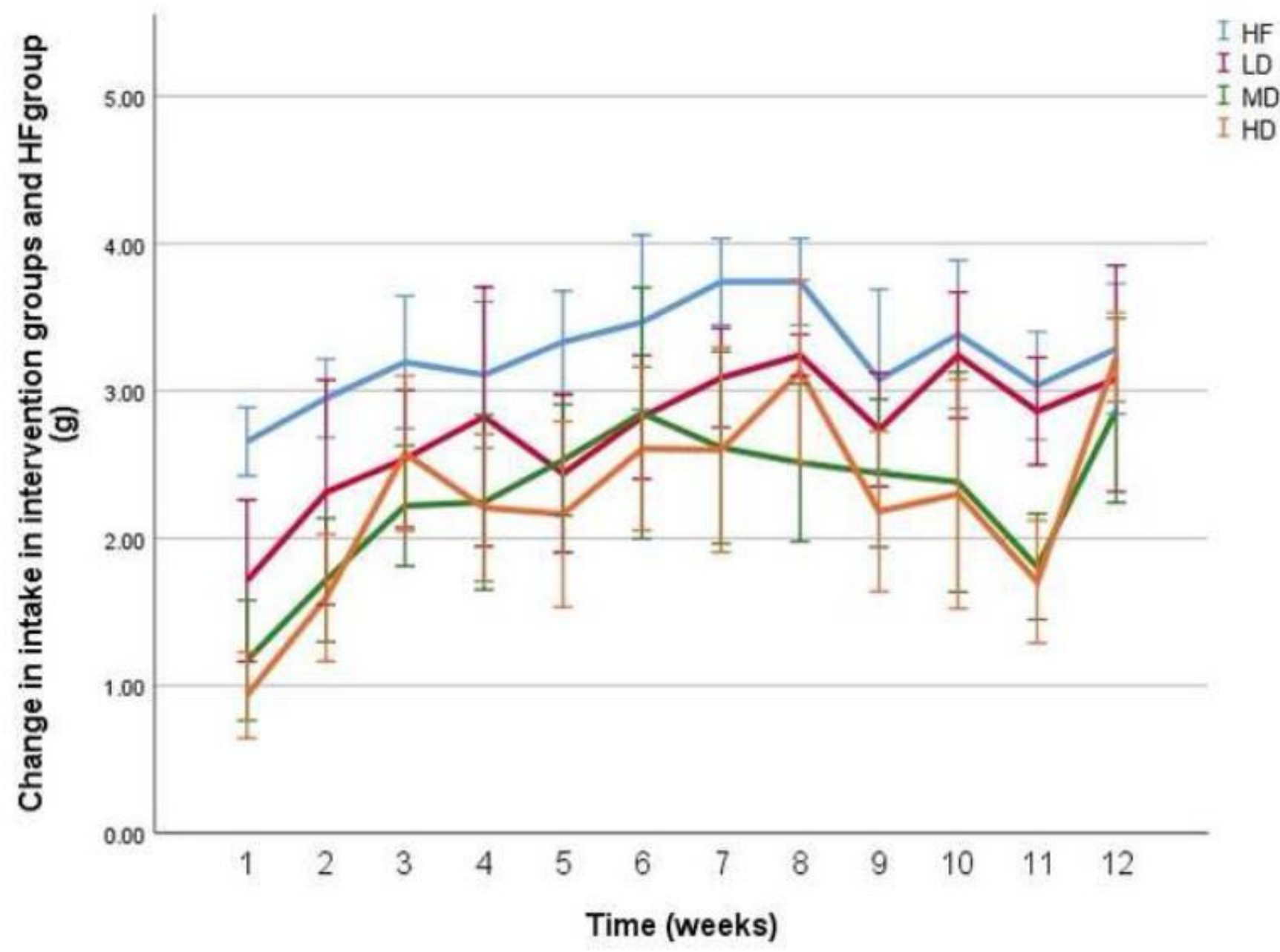

Figure 1

The food intake of each group was compared for 12 weeks $(x \rrbracket \pm s, g \rrbracket$ 


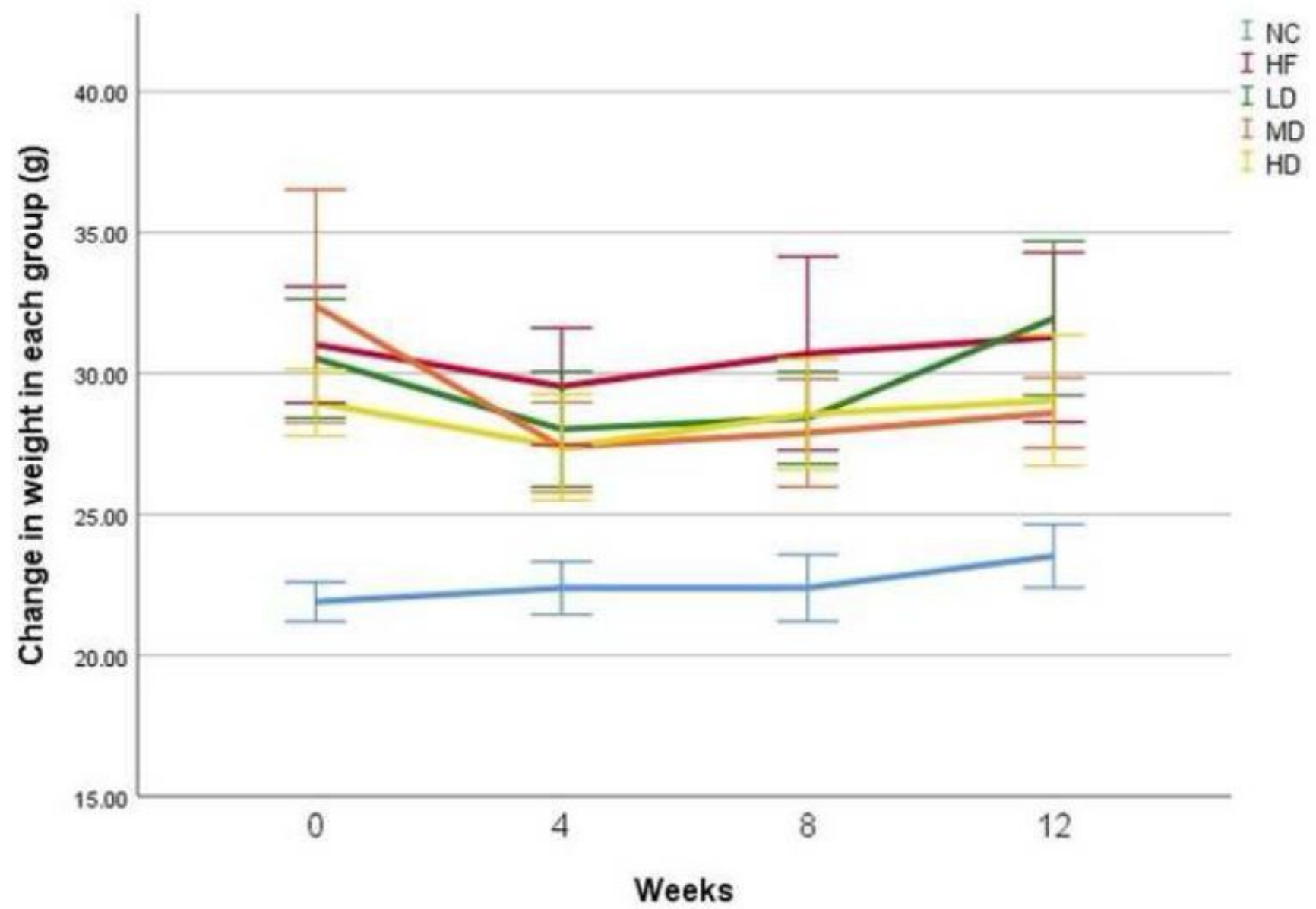

Figure 2

Changes in weight after 12 weeks treatment, relative to baseline 


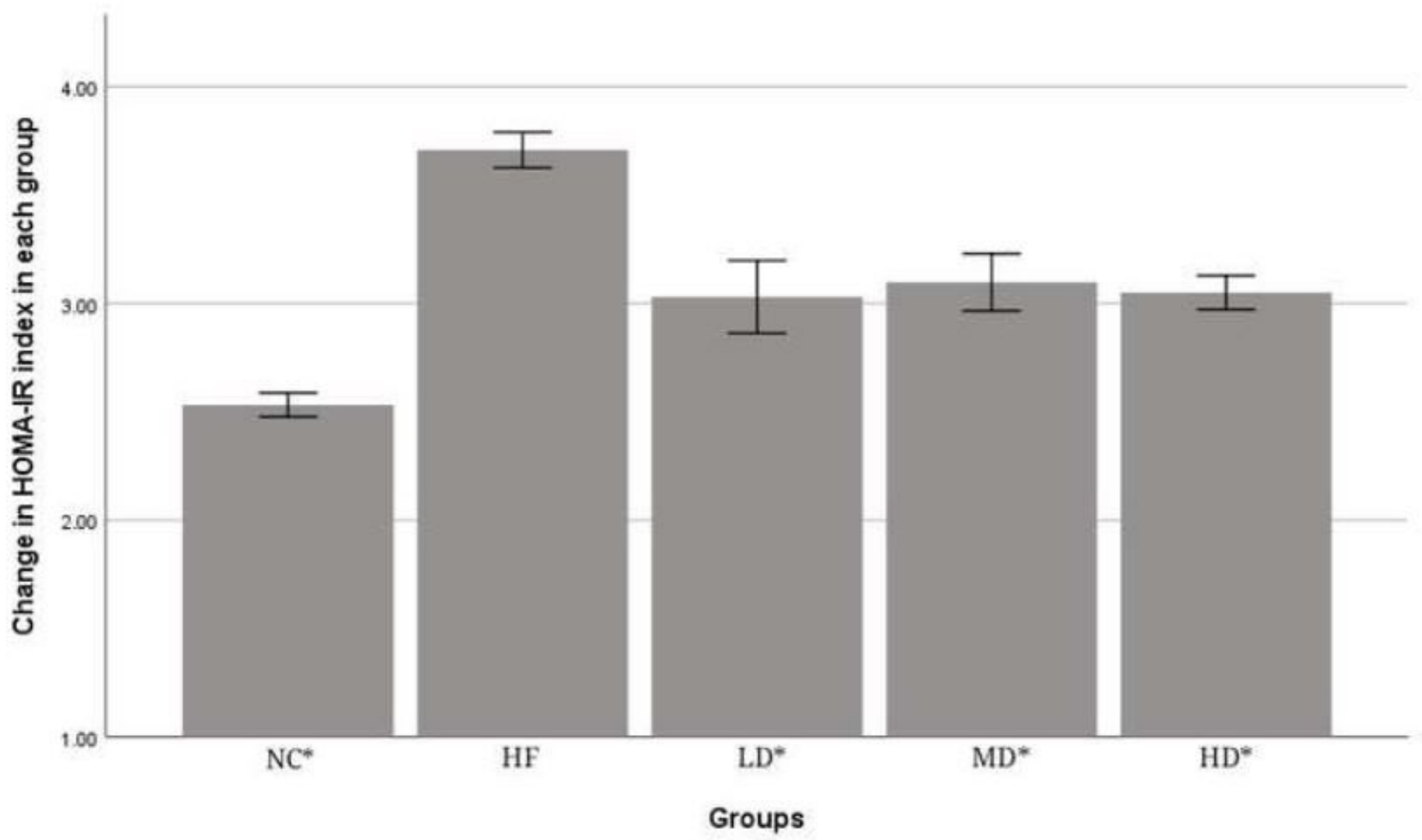

Figure 3

Change in the level of Homa-IR in each group ( $x \pm s, u g / L)$ 


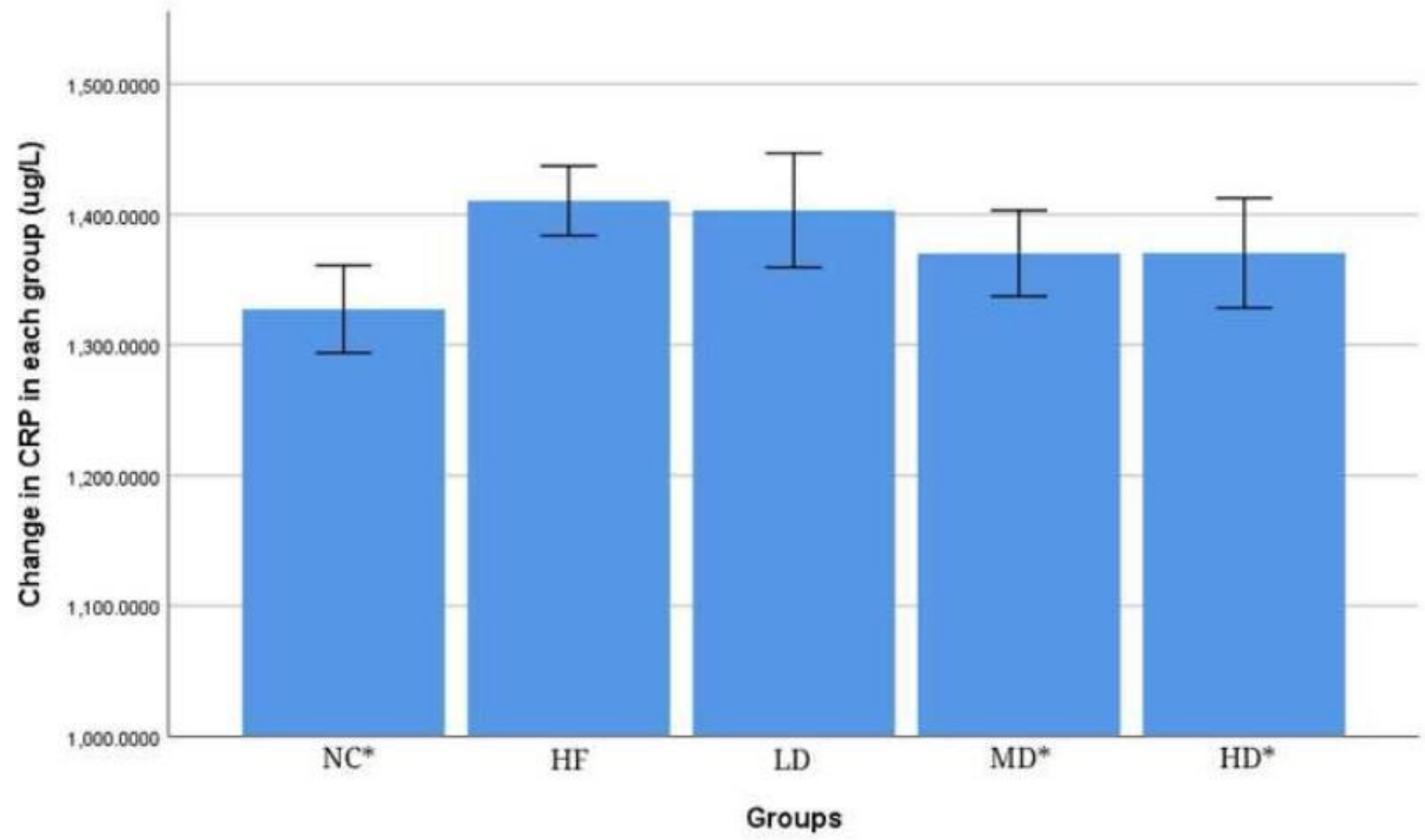

Figure 4

Change in the level of CRP in each group ( $x \pm s, u g / L)$ 


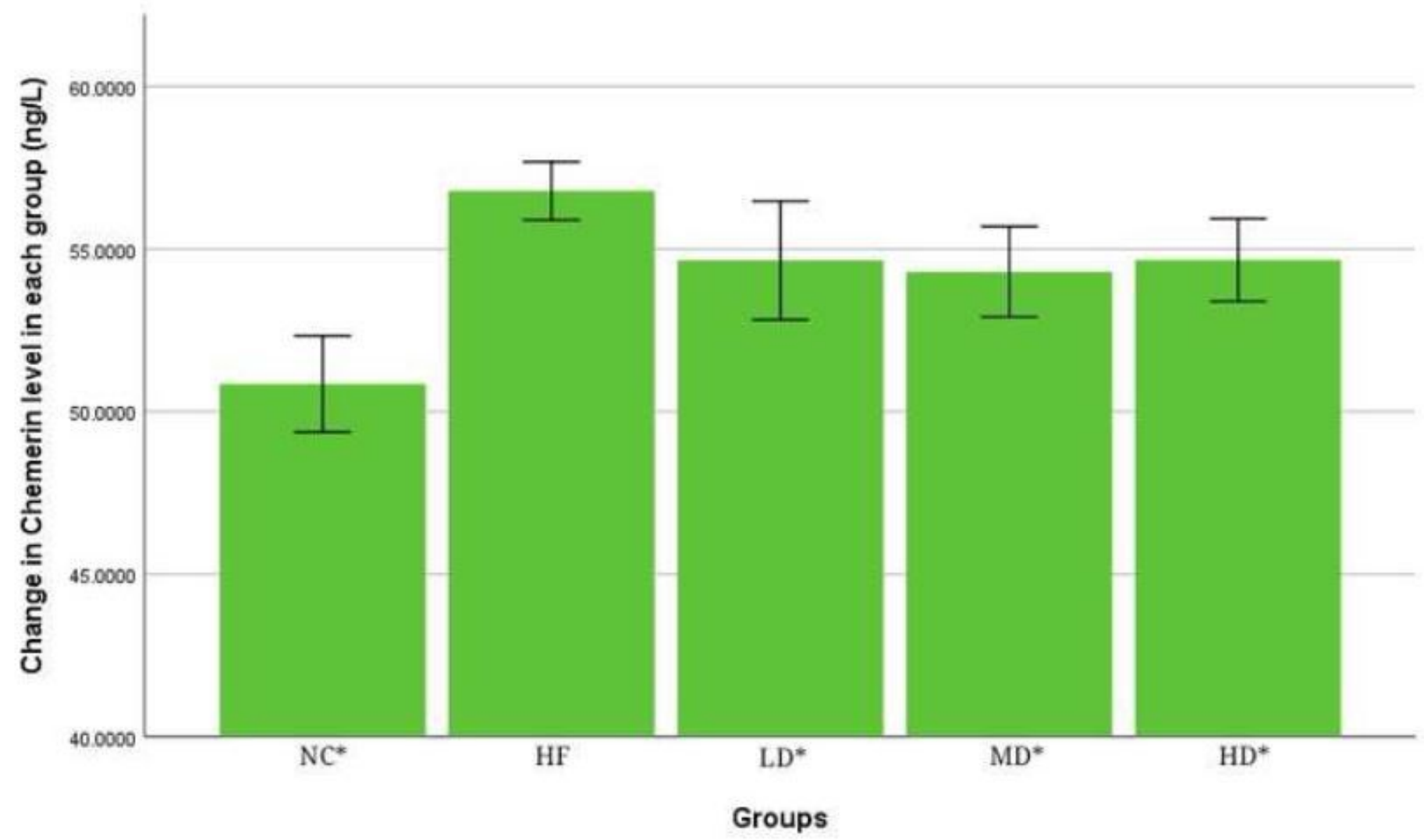

Figure 5

Change in the level of chemerin in each group ( $x \pm s, n g / L)$ 


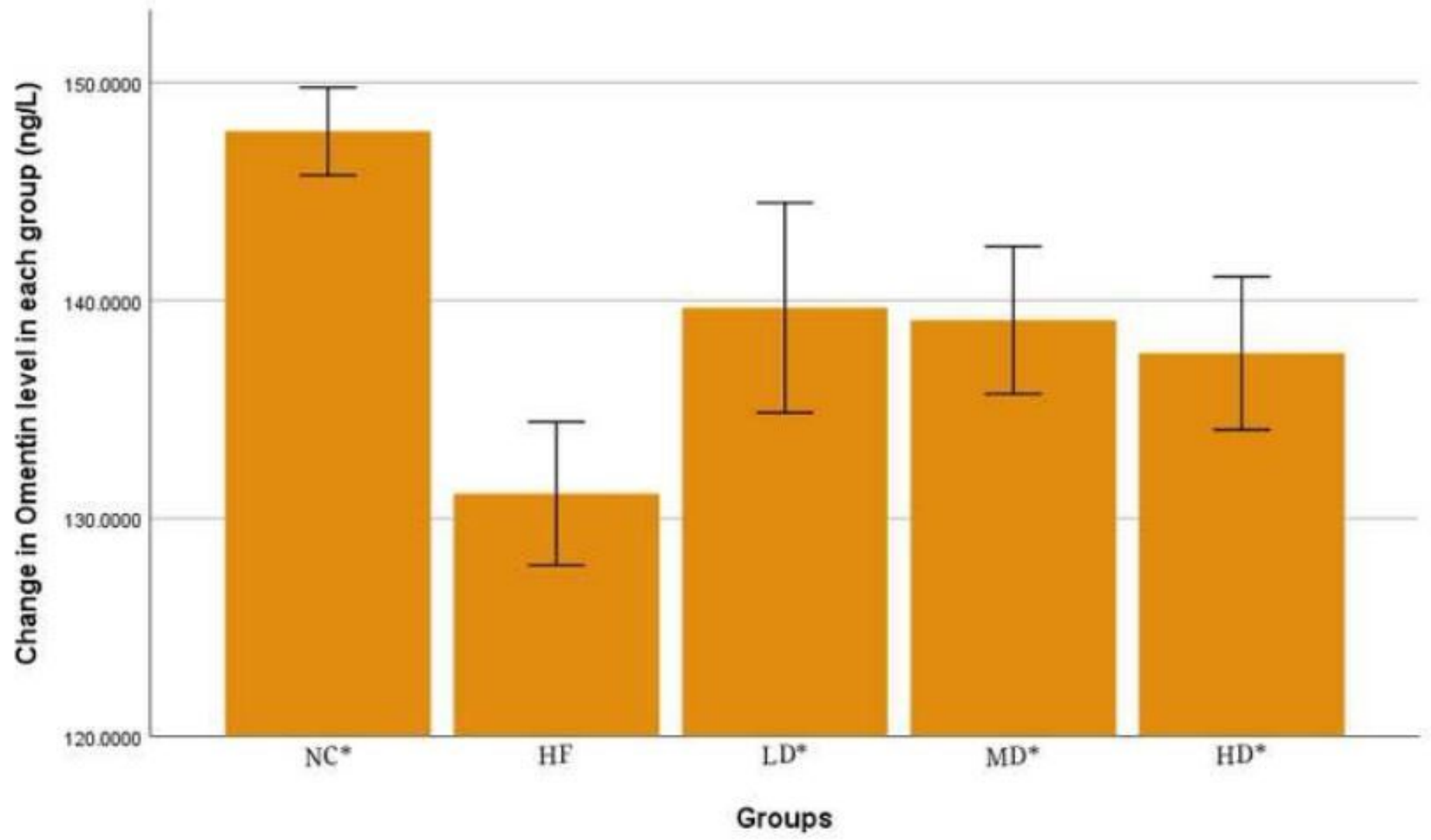

Figure 6

Change in the level of omentin in each group ( $x \pm s, n g / L)$ 